Contents available at: Sri Lanka Journals Online

\title{
Pulse-Width-Modulation Control of a Heat Pump Dryer with Cascade Evaporators and Parallel-Flow Condensers
}

A.J. Fernando ${ }^{1,2^{*}}$ K.S.P. Amaratunga ${ }^{3}$, D.A.N. Dharmasena ${ }^{3}$, R.M.R.D. Abeyrathna ${ }^{3}$, I.L. Gajasinghe ${ }^{2}$, H.S.T. Weerakoon $^{2}$, E.M.A.C. Ekanayake ${ }^{1}$ and D.M.S.P. Bandara ${ }^{4}$

1 Postgraduate Institute of Agriculture, University of Peradeniya, Sri Lanka

${ }^{2}$ Department of Agricultural Engineering and Soil Science, Faculty of Agriculture, Rajarata University of Sri Lanka

${ }^{3}$ Department of Agricultural Engineering, Faculty of Agriculture, University of Peradeniya, Sri Lanka

${ }^{4}$ National Institute of Postharvest Management, Anuradhapura, Sri Lanka

\section{ARTICLE INFO}

\section{Article history:}

Received: 30 June 2021

Revised version received: 20 September 2021

Accepted: 11 October 2021

Available online: 01 January 2022

\section{Keywords:}

Condensation

Drying

Evaporation

Heat pump

Pulse width modulation

\section{Citation:}

Fernando, A.J., Amaratunga, K.S.P., Dharmasena, D.A.N., Abeyrathna, R.M.R.D., Gajasinghe, I.L., Weerakoon, H.S.T., Ekanayake, E.M.A.C. and Bandara, D.M.S.P. (2022). Pulse-Width-Modulation Control of a Heat Pump Dryer with Cascade Evaporators and Parallel-Flow Condensers. Tropical Agricultural Research, 33(1): 09-17.

DOI: http://doi.org/10.4038/tar.v33i1.8532

Fernando A.J.

https://orcid.org/0000-0003-2292-547X

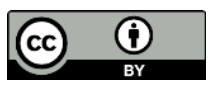

*author: jayaruwanifernando@gmail.com

\section{ABSTRACT}

Heat pump drying systems require a method to change the inflow air temperature of the drying chamber. Pulse-widthmodulation (PWM) technique with duty cycle provides a measure of controlling the voltage supplied to the electric motors. Therefore, we conducted this research to PWM control a heat pump dryer to change the air circuit parameters. In the Parallel-Flow condensers, inlet and outlet temperatures, and relative humidity, data were collected, and the average temperature values were recorded. The duty cycle was changed by developing a program using the Python programming language. An Excel-based psychrometric calculator was developed to analyze the collected data. The average condenser outlet temperatures were $56.6 \pm 0.1{ }^{\circ} \mathrm{C}, \quad 54.9 \pm 0.1{ }^{\circ} \mathrm{C}$, and $52.6 \pm 0.1^{\circ} \mathrm{C}$, and the average condenser inlet temperatures were $43.2 \pm 0.0{ }^{\circ} \mathrm{C}, 42.8 \pm 0.1{ }^{\circ} \mathrm{C}$, and $41.2 \pm 0.1{ }^{\circ} \mathrm{C}$ for $60 \%, 80 \%$, and $100 \%$ duty cycles, respectively. The power consumption rate of the condenser reduced with an increasing duty cycle. The results concluded that the PWM control system is a viable method to control the inflow air temperature to the drying chamber. 


\section{INTRODUCTION}

Pulse-width-modulation (PWM) controls specific analog quantities by the varying pulse width of a fixed frequency rectangular waveform (Toulson and Wilmshurst, 2012). The PWM generates variable-width pulses to represent the amplitude of an analog input signal. The output switching transistor is "ON" most of the time for a highamplitude signal and "OFF" most of the time for a low-amplitude signal. The digital nature (fully ON or OFF) of the PWM circuit is less costly to fabricate than an analog circuit that does not drift over time (Christ and Wernli Sr, 2013).

The PWM is used in many applications, ranging from communications to power control and conversion, such as controlling the speed of electric motors, the brightness of lights, ultrasonic cleaning applications, etc. (Ibrahim, 2014). A typical PWM signal pulsing its electrical signal by effectively chopping it into discrete parts is presented in Figure 1 . The duty cycle of PWM refers to the process "ON" time/Period.

Drying or dehydration is one of the most critical post-harvest treatments adopted worldwide to reduce spoilage and increase agricultural products' shelf life or storage durability. Removal of moisture in drying is a complex simultaneous heat and mass transfer process (Jayas and Singh, 2011). Agricultural commodities are sensitive to temperatures and require different temperatures to produce optimum quality products. Hot air in the temperature range of $45-60^{\circ} \mathrm{C}$ is necessary for the safe drying of agricultural commodities. Drying under a controlled condition of temperature and humidity brings the moisture level of the food products to a safer limit and ensures the better quality of products (Bhardwaj et al., 2017). The development of a dryer with variable air temperatures is a challenge in the food industry.

In response, heat pump (HP) drying systems are advantageous because the air cycle and refrigerant

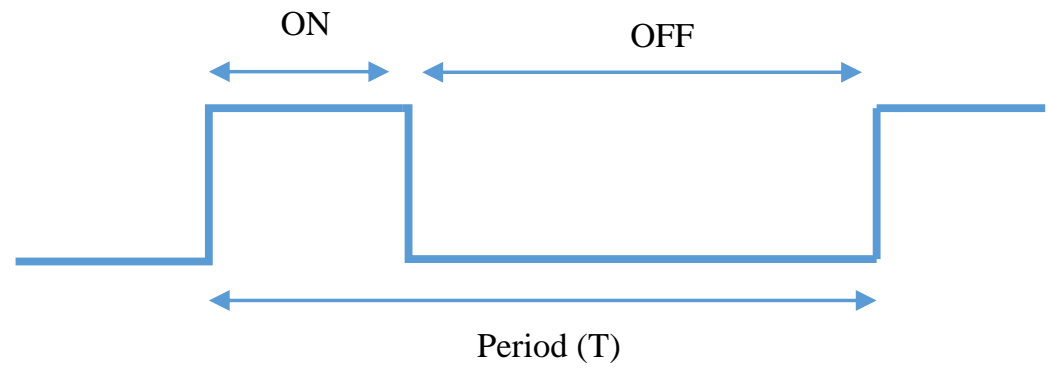

Figure 1. Typical PWM signal (Adapted from Ibrahim, 2014) cycle in the HP drying system provide opportunities to change the drying kinetics.

In the HP trying system (Figure 2), low-pressure refrigerant is compressed adiabatically (without transferring heat or mass) up to the level of high pressure in the compressor, which should allow condensation at the ambient temperature. Work is required to carry out this process, and this energy is supplied in the form of electrical power to drive the compressor motor. The refrigerant also gains in enthalpy during this compression process. At the condenser, the refrigerant condenses and transfers the latent heat of condensation to the surroundings. There is a loss of enthalpy in a constant pressure process. This heat energy is transferred to the drying chamber by the air flowing through the condenser. At the expansion valve, the liquid expands to a lower pressure at constant enthalpy, while at the evaporator, the liquid evaporates at constant pressure and gains in enthalpy. The energy for the evaporation process is supplied by the heated air flowing into the evaporator from the drying chamber (Heldman, 2012).

Moreover, HP drying is advantageous over conventional hot air drying due to its high drying efficiency, produce high-quality dried products, and high throughput, as identified by Chua et al. (2010) and Goh et al. (2011). As a result, HP drying is a widely used drying method applicable for agricultural products such as grains, fruits, vegetables, and condiments (Yousaf et al., 2020; Fernando et al., 2021; Singh et al., 2020; Venkatachalam et al., 2020).

Therefore, the objective of the research was to PWM control of an HP dryer with cascade evaporators and parallel flow condensers to manipulate the air circuit parameters. The properties of the air circuits were studied by changing the duty cycle in the PWM control system. 

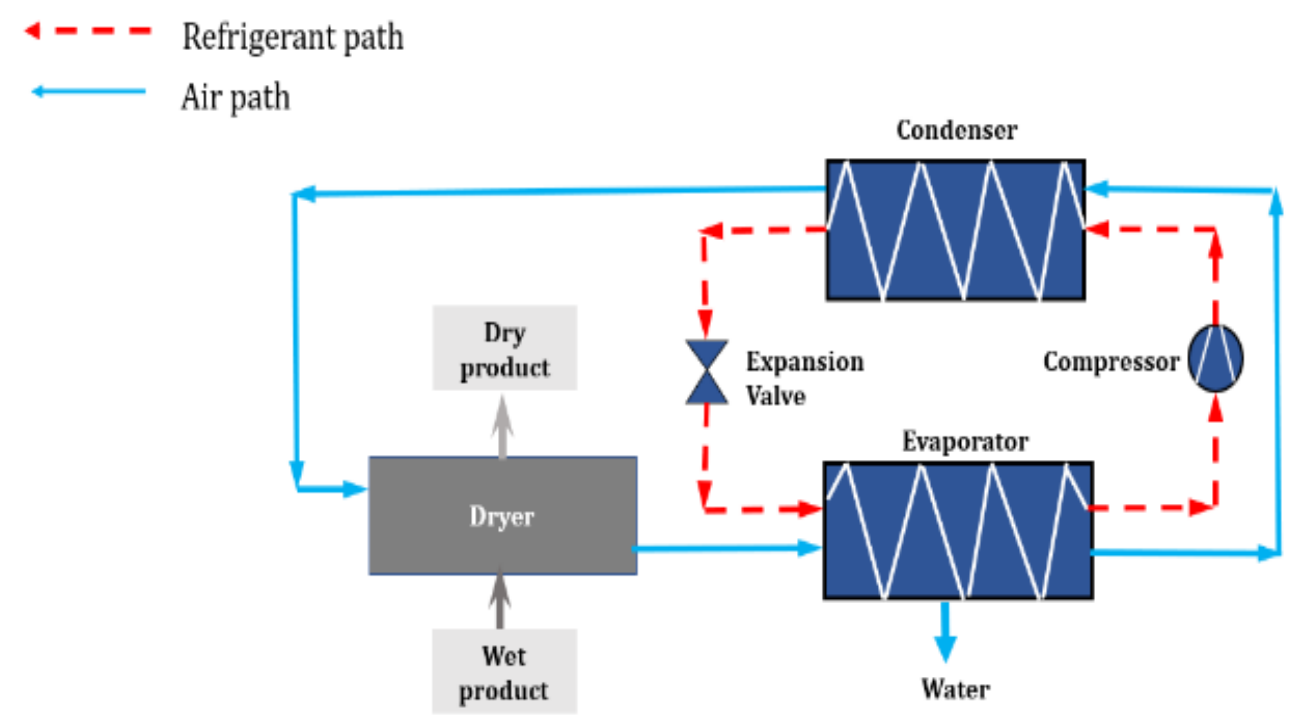

Figure 2. Schematic diagram of heat pump drying process (Adapted from Chua et al., 2002)

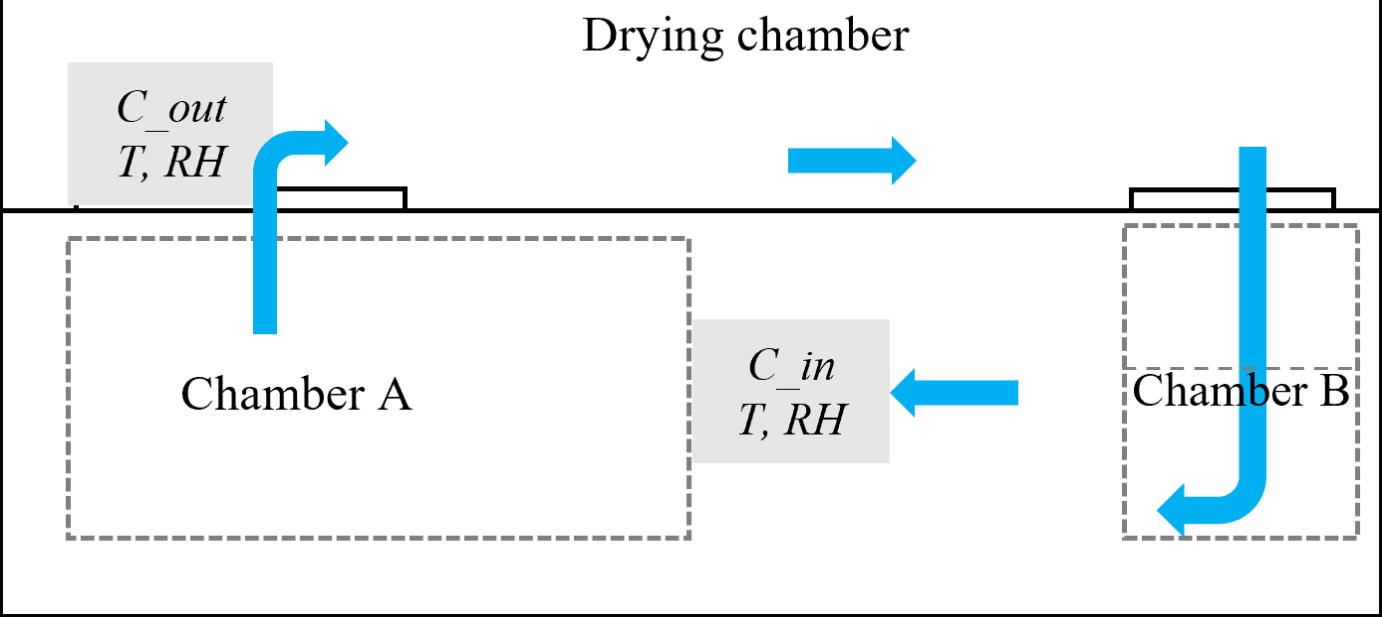

Figure 3. Heat pump dryer configuration (Chamber-A includes two HVAC outdoor units representing parallel condensers; Chamber-B includes two HVAC indoor units representing series evaporators; $C_{-}$in and $C_{-}$out refer to condenser in and condenser out; $T$ and $\mathrm{RH}$ refers to temperature and relative humidity.

\section{METHODOLOGY}

\section{Development of heat pump drying system}

The HP dryer in this study was designed and fabricated at the Department of Agricultural Engineering, University of Peradeniya, Sri Lanka. Figure 3 shows a schematic diagram of the HP dryer configuration. The HP dryer design configuration was an air-source closed-loop HP dryer system. Two HVAC (heating, ventilating, air conditioning) systems with a capacity of 9000 BTU and 12000 BTU were arranged as two indoor units in series and two outdoor units in parallel. 
Individual HVAC systems have four components: compressor, condenser, expansion valve, and evaporator. The outdoor unit includes the compressor and the condenser, while the indoor unit includes the expansion valve and the evaporator. The refrigerant used in both systems was R22. The drying chamber has a direct inlet from the outdoor units and a direct outlet to indoor units. The air flowing out the drying chamber feeds into the two indoor units in series. The air moving out of the second indoor unit feeds into the two condensers in parallel. The air flowing out of the outdoor units feeds into the drying chamber.

\section{Development of control system}

A fixed high condensing pressure can result in fan power saving (Yan et al., 2014) in a refrigeration system. However, Lu et al. (2016) and Yu and Chan (2006) used variable speed condenser fans to change the process parameters in HVAC systems. Therefore, a PWM technique with the duty cycle was adopted to the two condenser fan motors of the outdoor units. The PWM system was developed using microcontrollers and Solid-state Relay (SSR) modules. The microcontroller used for the study was Raspberry Pi 3 Model B+, which has 40 GPIO pins, and the operations system was New Out of Box Software (NOOBS).

\section{Data acquisition system}

We developed the data acquisition system using six DHT22 sensors connected to the Raspberry Pi 3 control system. The chamber-A inlet and outlet temperatures and relative humidity values were recorded, and the average values were calculated. We operated the HP dryer for one hour in each duty cycle and collected data in the last 20 minutes of each trial.

\section{Model development for the HVAC outdoor unit}

Energy balance principle was used to develop a model to find the capacity of chamber A. Equation 1 shows the developed model.

$$
\begin{gathered}
\qquad E_{\text {in }}=E_{\text {out }} \\
\begin{array}{l}
\text { Energy supplied to the condenser units } \\
=\text { Energy released to the air }
\end{array} \\
Q_{\text {unit }}=\left(h_{o, \text { out }}-h_{o, \text { in }}\right) \times m_{a} \quad \text {....... Equation } 1
\end{gathered}
$$

\section{Psychrometric calculator}

The psychrometric relationships were obtained from ASHRAE Fundamentals (2013), and an Excelbased psychrometric calculator was developed. The calculator was tested for the given temperature range. The calculator was used to find the capacity $\left(Q_{u n i t}\right)$ expressed in Equation 1.

\section{Statistical analysis}

We recorded the chamber-A inlet and outlet temperature in each duty cycle and the variation chamber-A outlet temperature with different duty cycles. The relationship between duty cycle and chamber-A outlet temperature was obtained. Further, chamber-A power consumption variation with duty cycle for the experimental time was obtained.

\section{RESULTS AND DISCUSSION}

\section{PWM control system}

The Raspberry pi and the SSR modules were connected to develop the PWM system. The PWM is a command controller that reduces the average power by pulsing its electrical signal by effectively chopping it into discrete parts. Modulation of those pulses' width allows controlling condenser fan motor rpm according to the requirement. The voltage supplied to the condenser fans was controlled through PWM to obtain different duty cycles. Duty cycles were changed from $0-100 \%$ and measured the air velocity. The duty cycles above $60 \%$ provided a considerable air velocity. Therefore, three duty cycles, $60 \%, 80 \%$, and $100 \%$, were selected based on preliminary data (data not reported).

The GPIO pin 4 of Raspberry Pi was used to supply input voltage to the SSR modules connected to the HP dryer condenser fan motors. A program code was developed using the python programming language to acquire the required duty cycles for the experiment.

Each average temperature from three sensor modules at condenser inlet and outlet were outputting in the program. The PWM control system, which acquires temperature data in different duty cycles is shown in Figure 4. 


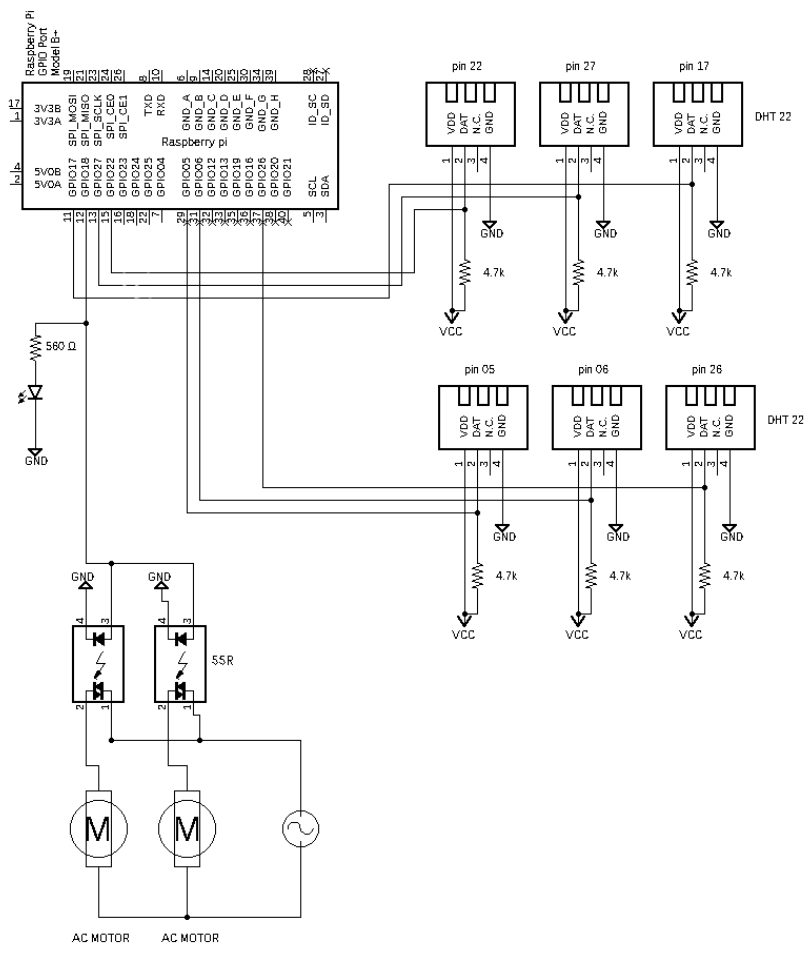

Figure 4. PWM control system for heat pump dryer

\section{Variation of chamber-A temperature}

The condenser inlet and outlet temperature varied with duty cycles. The average condenser outlet temperature in the last quarter of the experiment was $56.6 \pm 0.1{ }^{\circ} \mathrm{C}, 54.9 \pm 0.1{ }^{\circ} \mathrm{C}$, and $52.6 \pm 0.1{ }^{\circ} \mathrm{C}$ for $60 \%, 80 \%$, and $100 \%$ duty cycles simultaneously (Figures 5, 6, and 7). Thus, through changing the motor frequency, the capacity output rises decreases, and the capacity modulation allows for accurate temperature and humidity control (Ko et al., 2021).

The condenser outlet temperature was higher than the condenser inlet temperature because of the heat generation process in the condenser. The condensation of the refrigerant released heat energy, and this energy transferred to the surrounding air. The air flowing through the condenser gains this energy and thereby increases its temperature. The condenser inlet and outlet temperature differences were $13.4,12.1$, and 11.3 ${ }^{\circ} \mathrm{C}$ for $60 \%, 80 \%$, and $100 \%$ duty cycles, and respective condenser inlet temperatures were $43.2 \pm 0.0{ }^{\circ} \mathrm{C}, 42.8 \pm 0.1{ }^{\circ} \mathrm{C}$, and $41.2 \pm 0.1{ }^{\circ} \mathrm{C}$. Higher temperature differences indicate higher heat energy accumulation in the condenser.

Figure 8 shows the variation of temperature at the condenser outlet in different duty cycles.
Condenser outlet temperature decreases with increasing duty cycle. Thus, the average condenser outlet temperature in the last quarter of the experiment was $56.6 \pm 0.1{ }^{\circ} \mathrm{C}, 54.9 \pm 0.1{ }^{\circ} \mathrm{C}$, and $52.6 \pm 0.1{ }^{\circ} \mathrm{C}$ for $60 \%, 80 \%$, and $100 \%$ duty cycles simultaneously. At low duty cycles in the condenser motor, the heat transfer rate reduces. Therefore, air gains a higher temperature. But with increasing the duty cycle, heat transfer rate and the airflow rates in the condenser increase.

A linear relationship was observed for duty cycle vs. chamber-A outlet temperature. The equation was $y=-0.1 x+62.7$ with $R^{2}$ of 0.9926 , where $y$ denotes chamber-A outlet temperature, and $\mathrm{x}$ denotes the duty cycle of condenser fans. The energy consumption was calculated by the enthalpy difference stated in the developed model (Equation 1). The Excel-based psychrometric chart was used as a tool in developing a relationship with enthalpy difference at different time intervals. The chamber-A power consumption at different duty cycles has shown in Figure 9. The power consumption has been reduced with the increasing duty cycle. The less heat transfers from the refrigerant to the air at the high duty cycles cause high heat energy accumulation in chamber A. 


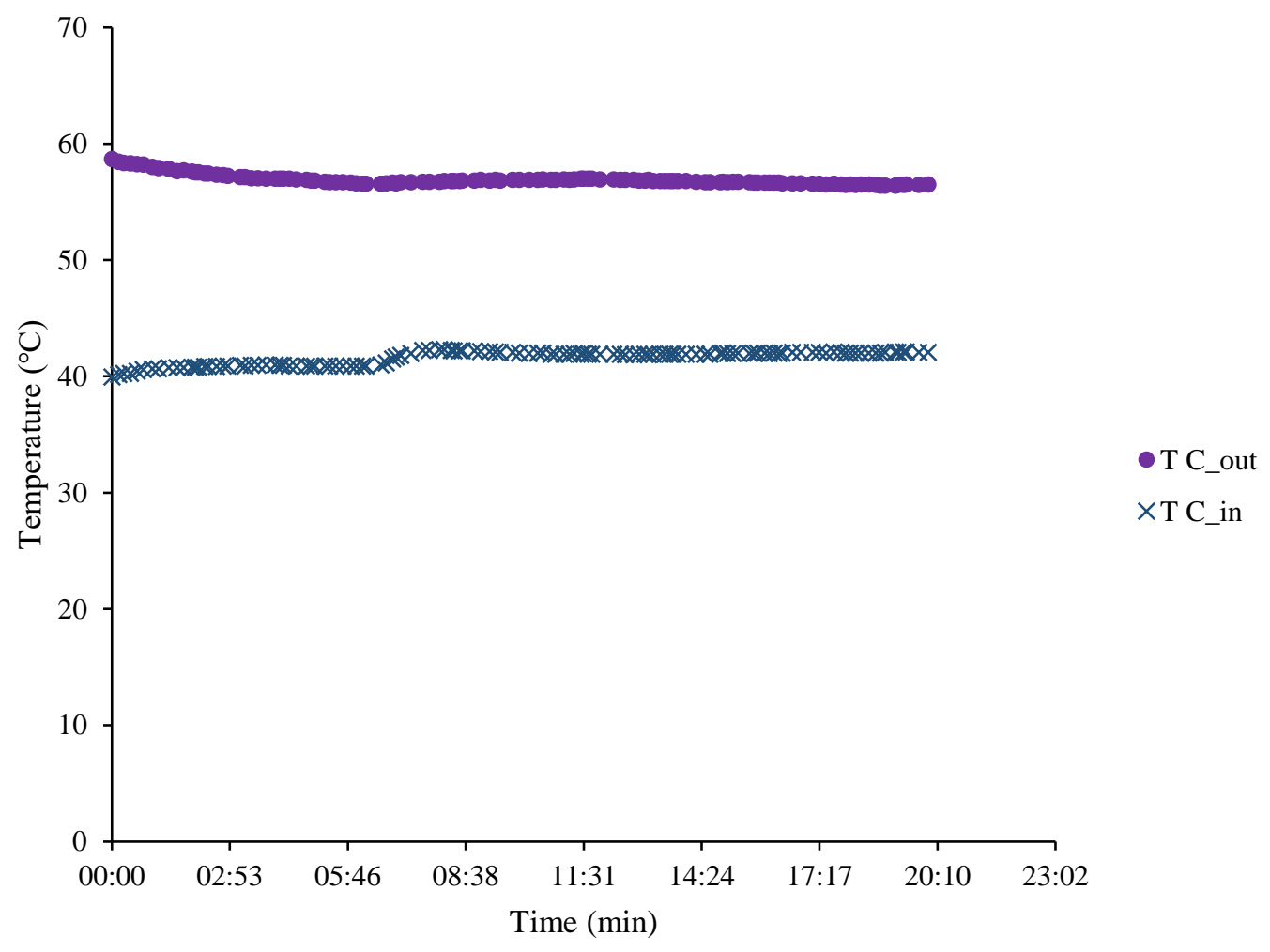

Figure 5. Chamber-A temperatures at $60 \%$ duty cycle

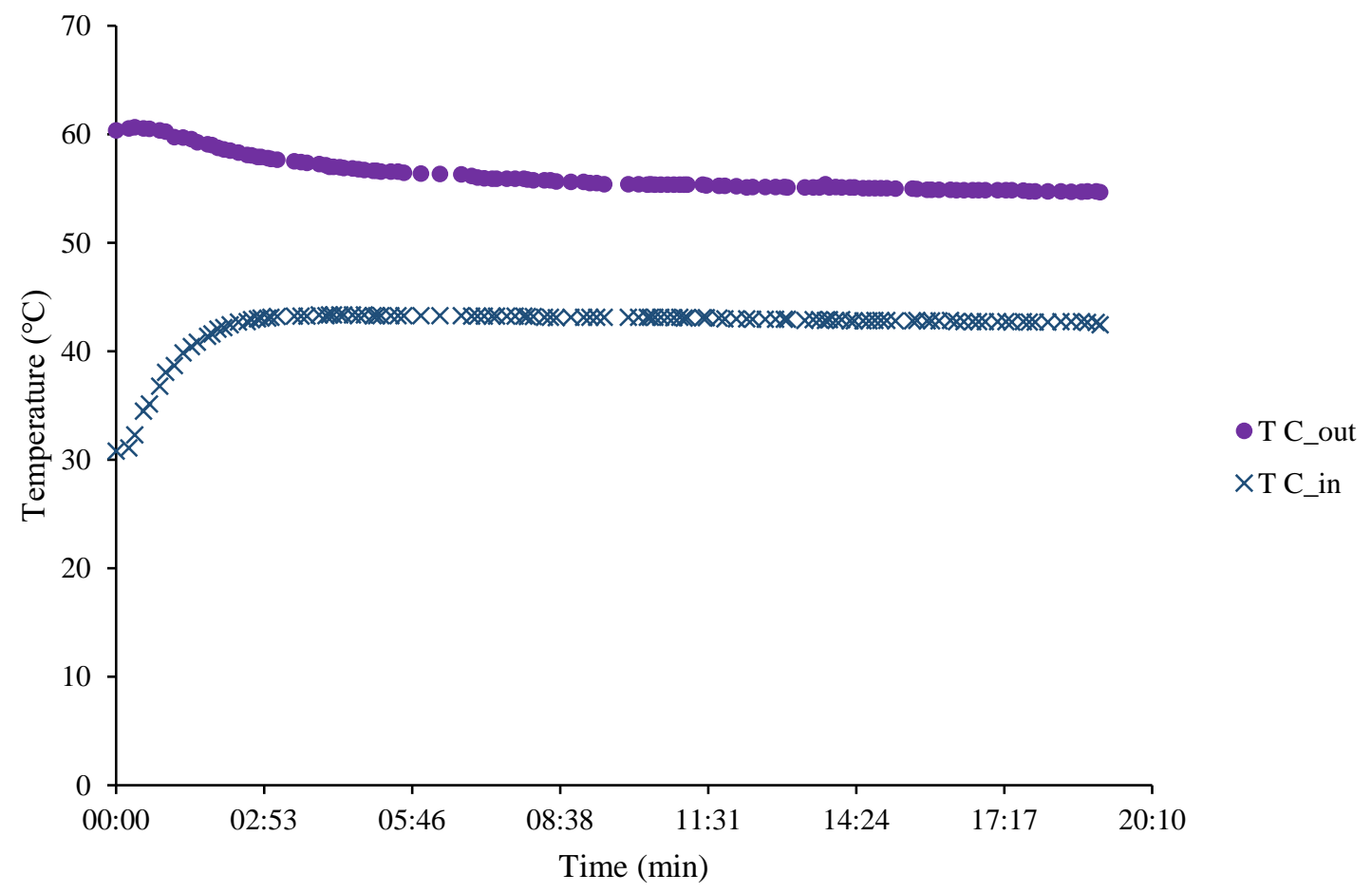

Figure 6. Chamber-A temperatures at $80 \%$ duty cycle 


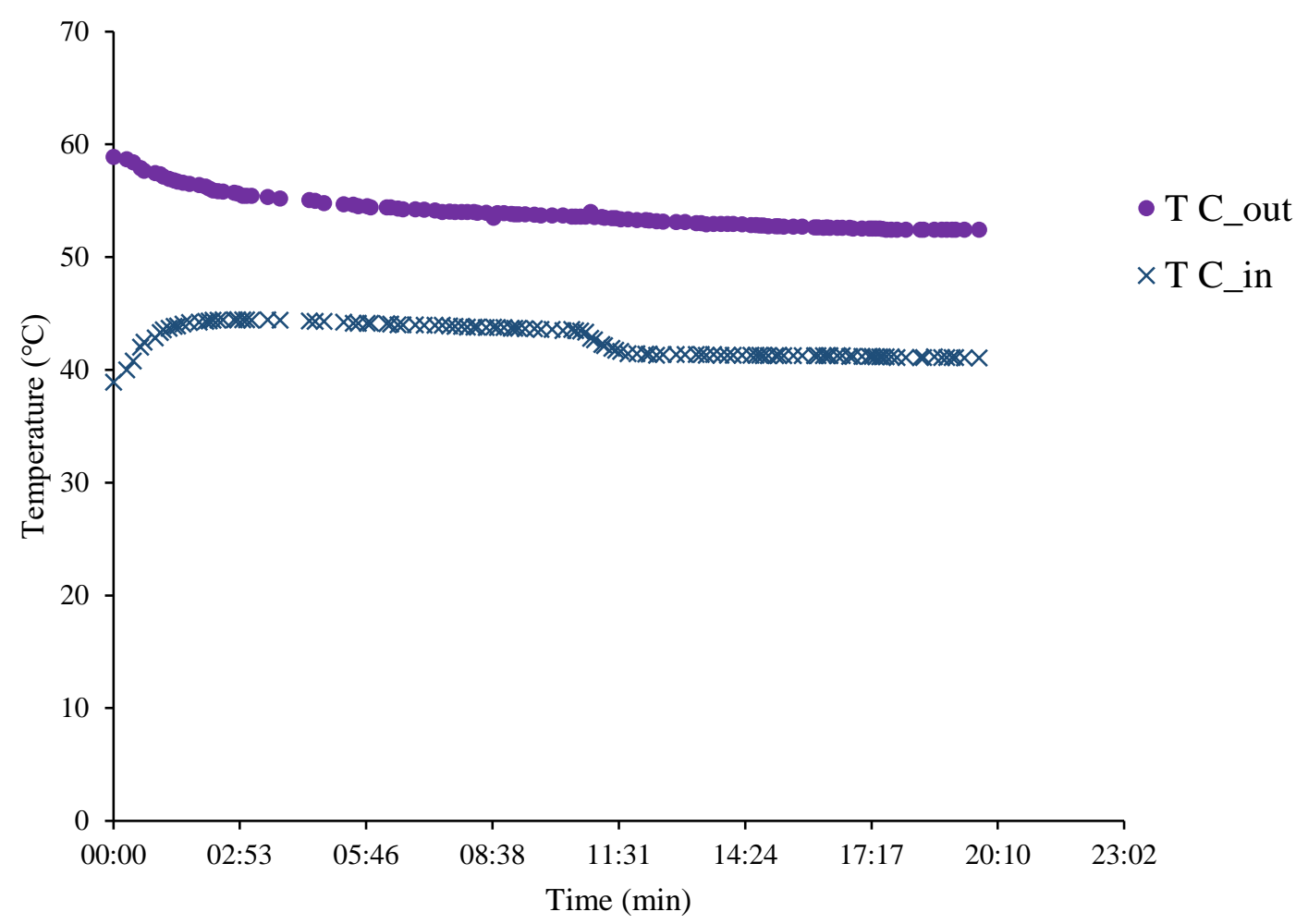

Figure 7. Chamber-A temperatures at $\mathbf{1 0 0 \%}$ duty cycle

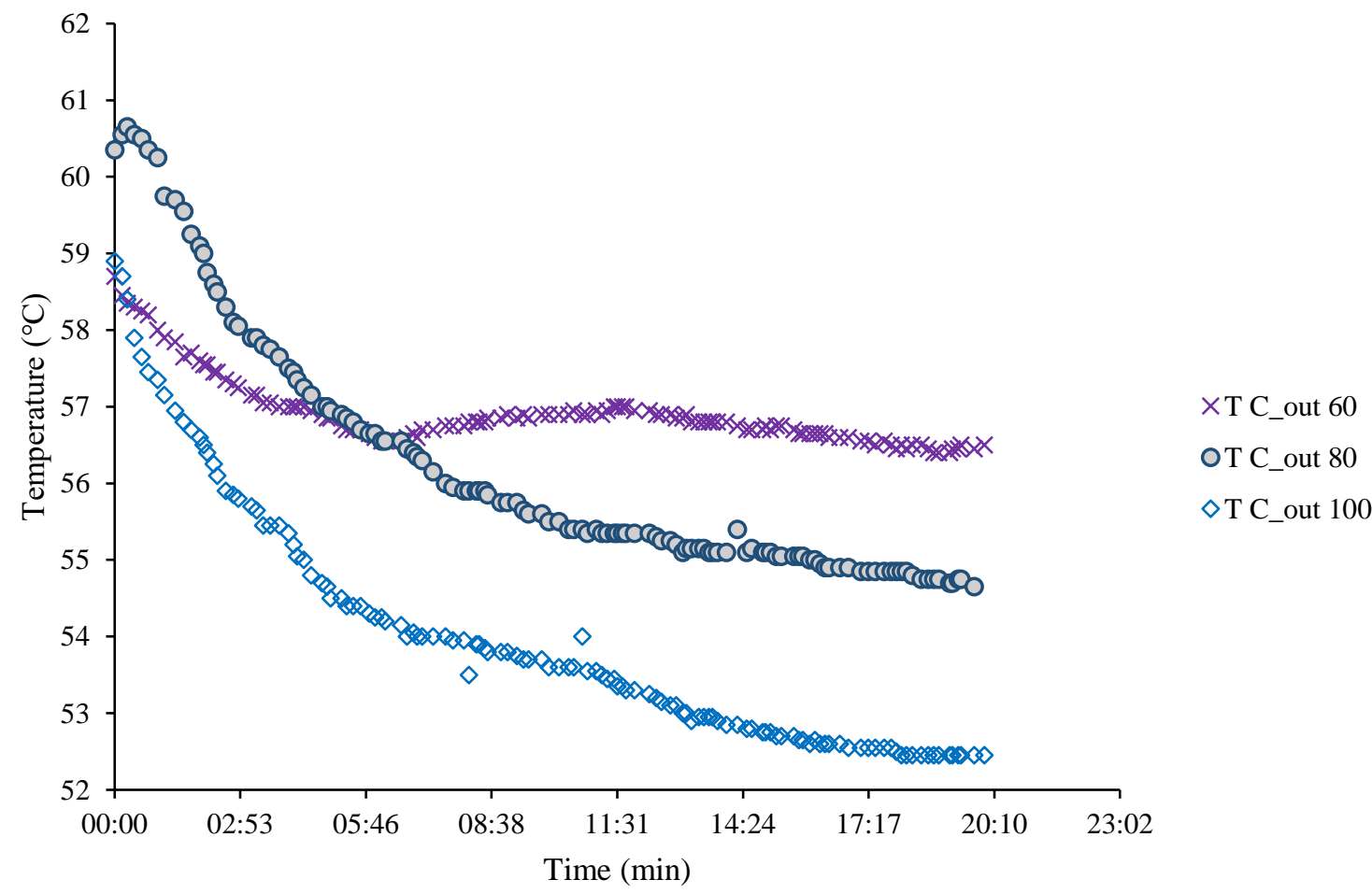

Figure 8. Variation of temperature at the Chamber-A outlet in different duty cycles 


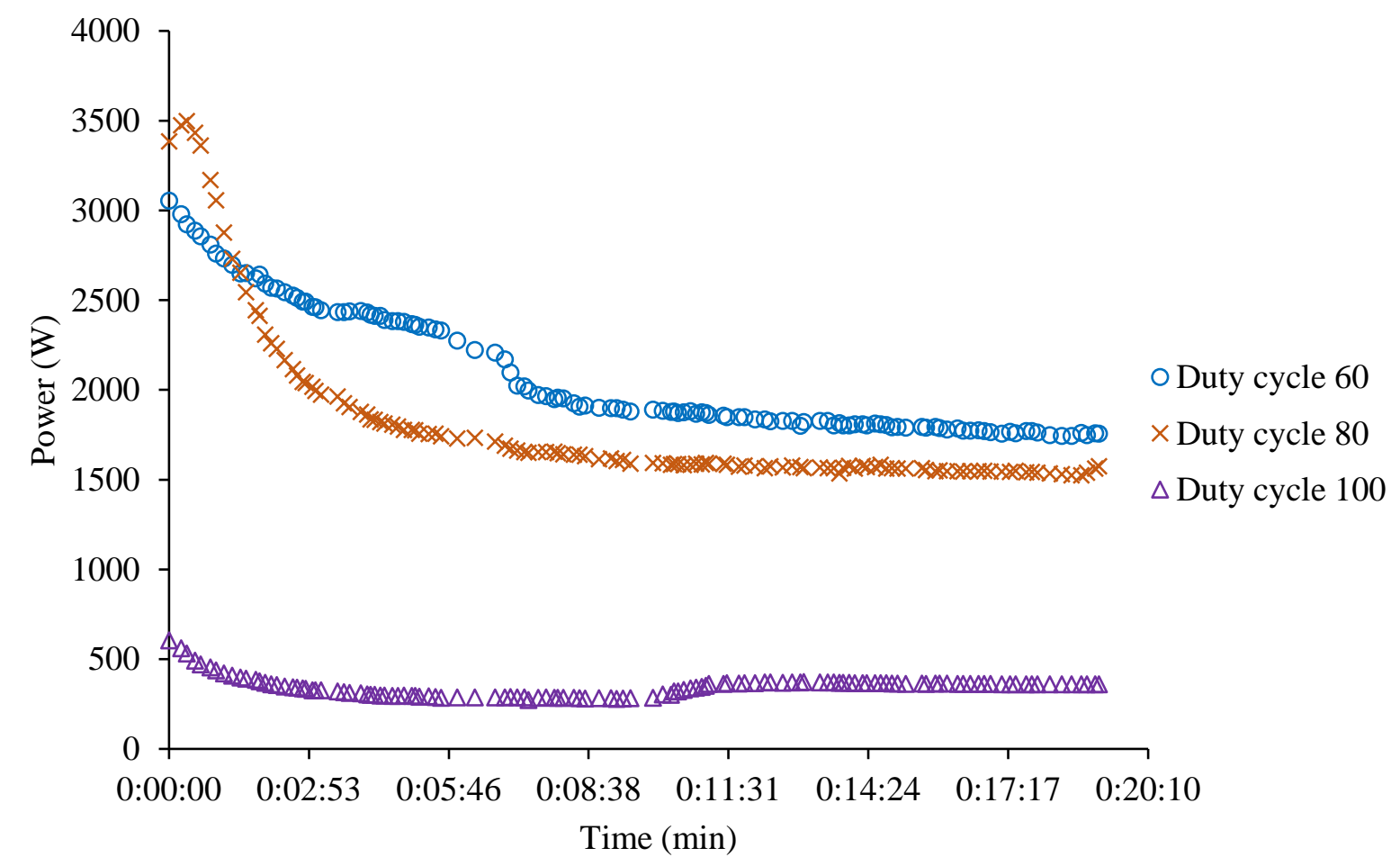

Figure 9. Variation of chamber-A power consumption with duty cycle

\section{CONCLUSIONS}

The hardware for the PWM control system was developed, and the program code was compiled and the required duty cycles, $60 \%, 80 \%$, and $100 \%$ were provided. Respective average condenser outlet temperatures were $56.6 \pm 0.1^{\circ} \mathrm{C}, 54.9 \pm 0.1^{\circ} \mathrm{C}$, and $52.6 \pm 0.1{ }^{\circ} \mathrm{C}$, and the average condenser inlet temperatures were $43.2 \pm 0.0{ }^{\circ} \mathrm{C}, 42.8 \pm 0.1{ }^{\circ} \mathrm{C}$, and $41.2 \pm 0.1{ }^{\circ} \mathrm{C}$, respectively. Further, the power consumption rate of the condenser was reduced with an increasing duty cycle. The duty cycle changes can control the voltage supply to the condenser fan motors and thereby regulates the condensers' outlet temperatures by modifying heat transfer rates and airflow rates. In conclusion, the PWM control system could be successfully applied to the HP dryer to manipulate the air circuit parameters. It would support obtaining different temperatures for drying various food products.

\section{ABBREVIATIONS}

T C_out - chamber A/condensers' outlet temperature $\left({ }^{\circ} \mathrm{C}\right)$

T C_in - chamber A/condensers' inlet temperature $\left({ }^{\circ} \mathrm{C}\right)$

T C_out 60 - chamber A/condensers' outlet temperature at $60 \%$ duty cycle $\left({ }^{\circ} \mathrm{C}\right)$
T C_out 80 - chamber A/condensers' outlet temperature at $80 \%$ duty cycle $\left({ }^{\circ} \mathrm{C}\right)$

T C_out 100 - chamber A/condensers' outlet temperature at $100 \%$ duty cycle $\left({ }^{\circ} \mathrm{C}\right)$

${ }^{\circ} \mathrm{C}$ - Celsius

min - minutes

$\mathrm{h}_{\mathrm{o}, \mathrm{in}}$ - enthalpy of the air entering the chamber $\mathrm{A} /$ condensers $(\mathrm{kJ} / \mathrm{kg})$

$\mathrm{h}_{\mathrm{o}, \text { out }}$ - enthalpy of the air releasing the chamber $\mathrm{A} /$ condensers $(\mathrm{kJ} / \mathrm{kg})$

Qunit - chamber A/condensers' capacity (W)

RH - Relative Humidity (\%)

$E_{\text {in }}$ - Energy In

Eout - Energy Out

BTU - British Thermal Unit

GPIO - General Purpose Input/Output

HP - Heat Pump

HVAC - Heating, Ventilating, Air conditioning

NOOBS - New Out of Box Software

PWM - Pulse Width Modulation

SSR - Solid-State Relay

\section{REFERENCES}

Bhardwaj, A. K., Chauhan, R., Kumar, R., Sethi, M., \& Rana, A. (2017). Experimental investigation of an indirect solar dryer integrated with phase change material for drying Valeriana 
jatamansi (medicinal herb). Case studies in thermal engineering, 10, 302-314.

Christ, R. D., \& Wernli Sr, R. L. (2013). The ROV manual: a user guide for remotely operated vehicles. Butterworth-Heinemann. https:// doi.org/10.1016/C2011-0-07796-7

Chua, K. J., Chou, S. K., \& Yang, W. M. (2010). Advances in heat pump systems: A review. Applied Energy, 87(12), 3611-3624. https://doi.org/10.1016/j.apenergy.2010.06. 014

Chua, K. J., Chou, S. K., Ho, J. C., \& Hawlader, M. N. A. (2002). Heat pump drying: recent developments and future trends. Drying Technology, 20(8), 1579-1610. https://doi.org /10.1081/DRT-120014053

Fernando, A. J., Amaratunga, K. S. P., Madhushanka, H. T. N., \& Jayaweera, H. R. Y. S. (2021). Drying performance of coffee in a batch-type heat pump dryer. Transactions of ASABE, 64(4): 1237-1245.

Goh, L. J., Othman, M. Y., Mat, S., Ruslan, H., \& Sopian, K. (2011). Review of heat pump systems for drying application. Renewable and Sustainable Energy Reviews, 15(9), 4788-4796. https://doi.org/10.1016/j.rser.2011.07.072

Heldman, D. R. (2012). Food process engineering. Springer Science \& Business Media.

Ibrahim, D. (2014). Designing embedded systems with 32-bit PIC microcontrollers and MikroC. Newnes, USA. https://doi.org/10.1016/ C2011-0-06919-3

Jayas D.S. \& Singh C.B. (2011). Drying of Agricultural Products. In: Gliński J., Horabik J., Lipiec J. (eds) Encyclopedia of Agrophysics. Encyclopedia of Earth Sciences Series. Springer, Dordrecht. https://doi.org/10.1007 /978-90-481-3585-1_44

Ko, G. S., Raza, W., \& Park, Y. C. (2021). Capacity control of a vehicle air-conditioning system using pulse width modulated duty cycle compressor. Case Studies in Thermal Engineering, 26, 100986. https://doi.org/10. 1016/j.csite.2021.100986

Lu, W., Meng, Z., Sun, Y., \& Zhu, H. (2016). Optimal fan speed and compression ratio of an aircondensed vapor-compression ammonia recycling system. International Journal of
Refrigeration, 67, 319-329. https://doi.org/ 10.1016/j.ijrefrig.2016.03.009

Singh, A., Sarkar, J., \& Sahoo, R. R. (2020). Experimental energy-exergy performance and kinetics analyses of compact dual-mode heat pump drying of food chips. Journal of Food Process Engineering, 43(6), e13404. https://doi.org/10.1111/jfpe.13404

Toulson, R. \& Wilmshurst, T. (2012). Chapter 4 analog output. In Toulson, R. and Wilmshurst, T., editors, Fast and Effective Embedded Systems Design, pages 57-75. Newnes, Oxford. https://doi.org/10.1016/C2015-0-00101-0

Venkatachalam, S. K., Vellingri, A. T., \& Selvaraj, V. (2020). Low-temperature drying characteristics of mint leaves in a continuousdehumidified air-drying system. Journal of Food Process Engineering, 43(4), e13384. https://doi.org/10.1111/jfpe.13384

Yan, Q. S., Shi, W. X., \& Tian, C. Q. (2014). Refrigeration technology for air conditioning. China Architecture Building Press, Beijing.

Yousaf, K., Liu, H., Gao, X., Liu, C., Abbas, A., Nyalala, I., \& Chen, K. (2020). Influence of environmental conditions on drying efficiency and heat pump performance in closed and open loop drying of paddy. Drying Technology, 38(16), 2217-2230. https://doi.org/ 10.1080/07373937.2019.1691011

Yu, F. W. \& Chan, K. T. (2006). Improved condenser design and condenser-fan operation for aircooled chillers. Applied Energy, 83(6), 628648. https://doi.org/10.1016/j.apenergy. 2005.05.007 